\title{
New strategies for drug discovery: activation of silent or weakly expressed microbial gene clusters
}

\author{
Kozo Ochi • Takeshi Hosaka
}

Received: 27 September 2012 /Revised: 23 October 2012 / Accepted: 24 October 2012 /Published online: 11 November 2012

(C) The Author(s) 2012. This article is published with open access at Springerlink.com

\begin{abstract}
Genome sequencing of Streptomyces, myxobacteria, and fungi showed that although each strain contains genes that encode the enzymes to synthesize a plethora of potential secondary metabolites, only a fraction are expressed during fermentation. Interest has therefore grown in the activation of these cryptic pathways. We review current progress on this topic, describing concepts for activating silent genes, utilization of "natural" mutant-type RNA polymerases and rare earth elements, and the applicability of ribosome engineering to myxobacteria and fungi, the microbial groups known as excellent searching sources, as well as actinomycetes, for secondary metabolites.
\end{abstract}

Keywords Silent gene activation - Strain improvement . Ribosome engineering $\cdot$ Rare earth elements

\section{Introduction}

Applied microbiology seeks, for example, to identify the latent activities of microorganisms and to enhance these activities at the industrial level by strain improvement. Current methods of strain improvement, ranging from classical random approaches to metabolic engineering, however, are either costly or laborintensive (Santos and Stephanopoulos 2008). Moreover, after 1970 , the rate of discovery of useful compounds declined

\footnotetext{
K. Ochi $(\bowtie)$

Department of Life Science, Hiroshima Institute of Technology,

Miyake 2-1-1, Saeki-ku,

Hiroshima 731-5193, Japan

e-mail: k.ochi.bz@it-hiroshima.ac.jp

T. Hosaka

Department of Bioscience and Biotechnology,

Faculty of Agriculture, Shinshu University,

8304 Minamiminowa,

Nagano 399-4598, Japan
}

progressively, despite the constant need for new and improved drugs to combat emerging and reemerging infectious diseases and cancer. Recent advances in DNA sequencing technologies have enabled multiple genomes to be sequenced rapidly and inexpensively. Streptomyces genome sequencing showed that each strain contains genes that encode the enzymes to synthesize 20 or more potential secondary metabolites (Bentley et al. 2002; Ikeda et al. 2003; Ohnishi et al. 2008), only a fraction of which are expressed during fermentation. These cryptic biosynthetic pathways may produce many novel bioactive compounds with the potential to rejuvenate stalled drug discovery pipelines. Methods to activate these silent biosynthetic pathways are thus of major interest. The key issue for the success of this approach is to find ways to induce or enhance the expression of cryptic or poorly expressed pathways to provide material for structure elucidation and biological testing. Thus, strategies for rapid strain improvement will likely shift from the improved expression of well-known, highly productive, secondary metabolites of fermentation to the expression of novel and often cryptic secondary metabolite pathways (Baltz 2011). This approach may solve the early stage discovery problems of: (a) inducing some level of expression of cryptic biosynthetic gene clusters [waking the sleeping genes] and (b) rapidly increasing product yields to obtain enough material to characterize chemically and biologically [early stage yield enhancement].

The notion of "ribosome engineering" originally came from the finding, that a Streptomyces lividans strain with an altered ribosomal S12 protein that confers streptomycin resistance produced abundant quantities of the blue-pigmented antibiotic actinorhodin, although $S$. lividans normally does not produce antibiotics due to the dormancy of the antibiotic biosynthesis genes (Shima et al. 1996). On the other hand, the bacterial alarmone ppGpp, produced on the ribosome, was found to bind to RNA polymerase (RNAP) (Artsimovitch et al. 2004), eventually initiating the production of antibiotics (Bibb 2005; Ochi 2007). This suggested that RNAP modification, by introducing 
a rifampicin resistance mutation, may mimic the ppGpp-bound form, activating the expression of biosynthetic gene clusters (Lai et al. 2002; Xu et al. 2002). Consequently, we have developed a method, termed ribosome engineering, to activate or enhance the production of secondary metabolites by targeting ribosomal protein $\mathrm{S} 12$, as well as other ribosomal proteins and translation factors, or RNAP, hypothesizing that bacterial gene expression may be increased dramatically by altering transcription and translation pathways.

Ribosome engineering is characterized by its applicability to both strain improvement and silent gene activation to identify novel secondary metabolites. The fundamental mechanism by which ribosome engineering affects antibiotic production has been summarized in earlier reviews (Ochi et al. 2004; Ochi 2007), as has the outline of this technology (Baltz 2011; Chiang et al. 2011; Olano et al. 2008; Xie et al. 2009). Therefore, the present review highlights recent advances on this topic.

\section{Impact on strain improvement}

Since many antibiotics, such as streptomycin, target the ribosome, ribosome mutants that confer antibiotic resistance may be obtained by simply selecting mutants on drug-containing plates, although some fraction of the mutants may be the ones affected in membrane permeability. Similarly, RNAP mutants may be obtained by growing bacteria on plates containing rifampicin that targets RNAP. This feasibility has yielded many successful examples of ribosome engineering, including the enhanced production of secondary metabolites and enzymes, as well as enhanced tolerance to toxic compounds such as 4-hydroxybenzoate (Table 1). Ribosome engineering was effective in enhancing the yield of secondary metabolites in a wide range of structural classes, including polyketides, macrolides, aminoglycosides, and nucleosides. Importantly, the K88E and K88R mutations in rpsL (polypeptide amino acid numbering according to Streptomyces coelicolor), which encodes the ribosomal protein $\mathrm{S} 12$, and the $\mathrm{H} 437 \mathrm{Y}$ and $\mathrm{H} 437 \mathrm{R}$ in $r p o B$, which encodes the RNAP $\beta$ subunit, were often effective (Table 1). In all these mutant strains of $S$. coelicolor, overproduction of actinorhodin correlated with higher expression of act II-ORF4, a pathway-specific positive regulator of actinorhodin synthesis. Combinations of these drug-resistance mutations further enhanced bacterial productivity (Tamehiro et al. 2003; Tanaka et al. 2009a). For example, the introduction of eight different mutations enhanced actinorhodin production by $S$. coelicolor 280 -fold (Wang et al. 2008) and the introduction of three mutations enhanced the production of the enzyme cycloisomaltooligosaccharide glucanotransferase by Paenibacillus agaridevorans 1,000-fold (Tanaka and Ochi, manuscript in preparation). Mutations in $r p s L$ enhanced expression of the frr gene, which encodes ribosome recycling factor (Hosaka et al. 2006), and overexpression of frr in Streptomyces avermitilis increased avermectin production, even in an industrial strain ( $\mathrm{Li}$ et al. 2010). Overexpression of frr may be a general method of boosting translation during the stationary phase, leading to reinforcement of secondary metabolism. The rif mutation S444F increased erythromycin production by Saccharopolyspora erythraea fourfold and metabolic changes induced by this mutation were analyzed in detail using DNA microarrays (Carata et al. 2009).

Construction of an amenable host organism for heterologous gene expression is a current goal for enhancing yield and activating cryptic gene clusters (Baltz 2010; Komatsu et al. 2010). Introduction of the rpsL K88R mutation into Streptomyces fradiae resulted in the efficient heterologous expression of secondary metabolite genes (Alexander et al. 2010). Moreover, introduction of the $r p s L \mathrm{~K} 88 \mathrm{E}$ and $r p o B$ S433L mutations into $S$. coelicolor enhanced the production of chloramphenicol and congocidine 40- and 30-fold, respectively (Gomez-Escribano and Bibb 2011), and mutations conferring resistance to lincomycin and kanamycin enhanced violacein production in Escherichia coli 41-fold (Ahmetagic and Pemberton 2011). Although the present review does not focus on the host organism system for heterologous expression of secondary metabolite gene clusters, the most updated review can be seen elsewhere (Komatsu et al. 2013).

The $r s m G$ gene encodes a $16 \mathrm{~S}$ rRNA methyltransferase, which methylates position G527 of the 530 loop of $16 \mathrm{~S}$ rRNA (Okamoto et al. 2007). Mutations of this gene in Streptomyces strains confer low-level resistance to streptomycin and cause preferential overexpression of the metK gene (at least in $S$. coelicolor), which encodes the enzyme $S$ adenosylmethionine (SAM) synthetase, eventually leading to an increase in intracellular SAM level (Nishimura et al. 2007). This increase, together with enhanced protein synthesis during the late growth phase, results in overproduction of antibiotic (Kim et al. 2003; Okamoto et al. 2003). Addition of SAM to the medium or propagation of $m e t K$ with multicopy plasmids also results in antibiotic overproduction by various Streptomyces spp. and other actinomycetes (Huh et al. 2004; Maharjan et al. 2008, 2012; Oh et al. 2010; Paudel et al. 2011; Saito et al. 2003; Shin et al. 2007; Sun et al. 2012; Wang et al. 2007; Zhao et al. 2006, 2010). Spontaneous $r s m G$ mutations arise at a high frequency $\left(10^{-4}-10^{-6}\right)$ (Nishimura et al. 2007; Okamoto et al. 2007). $r s m G$ mutation (and also ksgA mutation [Ochi et al. 2009]) harbors several mysterious features (Nodwell 2007) and is effective for not only enhanced antibiotic production but also activation of cryptic secondary metabolite biosynthetic genes (Tanaka et al. 2009b). When constructing strains combining low-level $(r s m G)$ and high-level $(r p s L)$ streptomycin resistance mutations, the mutations should be introduced in that order (Tanaka et al. 2009a). 
Table 1 Improvement of antibiotic/enzyme production and cell's physiology by subjecting to ribosome engineering

\begin{tabular}{|c|c|c|c|c|}
\hline Strain & Antibiotic/enzyme & Mutation & Comment & Reference \\
\hline \multicolumn{5}{|l|}{ Actinomycetes } \\
\hline S. coelicolor & Actinorhodin & $r p s L(\mathrm{~K} 88 \mathrm{E}$ or $\mathrm{K} 88 \mathrm{R})$ & Using relC mutant & Ochi et al. (1997) \\
\hline S. coelicolor & Actinorhodin & $r p s L(\mathrm{~K} 88 \mathrm{E})$ & Streptomycin resistance & Hesketh and Ochi (1997) \\
\hline S. coelicolor & Actinorhodin & $\operatorname{rps} L(\mathrm{P} 91 \mathrm{~S})$ & Paromomycin resistance & Okamoto-Hosoya et al. (2000) \\
\hline S. coelicolor & Actinorhodin & $\begin{array}{c}\operatorname{rps} L(\mathrm{~K} 88 \mathrm{E}) \text { gen } \\
r p o B(\mathrm{H} 437 \mathrm{Y})\end{array}$ & Triple mutation & Hu and Ochi (2001) \\
\hline S. coelicolor & Actinorhodin & $\operatorname{rpoB}(\mathrm{R} 440 \mathrm{H}$ or $\mathrm{Q} 424 \mathrm{~L})$ & $\begin{array}{l}\text { Using relA and } \\
\text { relC mutants }\end{array}$ & Xu et al. (2002) \\
\hline S. coelicolor & Actinorhodin & $r p s L(\mathrm{~K} 88 \mathrm{E})$ & Streptomycin resistance & Hosaka et al. (2006) \\
\hline S. coelicolor & Actinorhodin & $r s m G$ & Function-loss mutation & Nishimura et al. (2007) \\
\hline S. coelicolor & Actinorhodin & $\begin{array}{l}r p s L \text { gen } r p o B \text { par } \\
\text { gnt fus tsp lin }\end{array}$ & Octuple mutation & Wang et al. (2008) \\
\hline S. coelicolor & Actinorhodin & $\operatorname{rsm} G$ & Function-loss mutation & Tanaka et al. (2009a) \\
\hline S. coelicolor & Actinorhodin & $r s m G \operatorname{rsp} L(\mathrm{R} 86 \mathrm{P}$ or $\mathrm{K} 88 \mathrm{E})$ & Double mutation & Tanaka et al. (2009a) \\
\hline S. coelicolor & Actinorhodin & $r p s L(\mathrm{~K} 88 \mathrm{E})$ & Streptomycin resistance & Tanaka et al. (2009a) \\
\hline S. coelicolor & Actinorhodin & $r p s L(\mathrm{~K} 88 \mathrm{E}$ GI92) & $\begin{array}{l}\text { Double mutation with } \\
\text { paromomycin resistance }\end{array}$ & Wang et al. (2009a) \\
\hline S. coelicolor & Chloramphenicol & $r p s L(\mathrm{~K} 88 \mathrm{E}) r p o B(\mathrm{~S} 433 \mathrm{~L})$ & $\begin{array}{l}\text { Double mutation, } \\
\text { heterologous expression }\end{array}$ & $\begin{array}{r}\text { Gomez-Escribano } \\
\text { and Bibb (2011) }\end{array}$ \\
\hline S. coelicolor & Actinorhodin & ery & Erythromycin resistance & Imai et al. (2012) \\
\hline S. lividans & Actinorhodin & $r p s L(\mathrm{~K} 88 \mathrm{E})$ & S. lividans TK24 with str & Shima et al. (1996) \\
\hline S. lividans & Actinorhodin & $\operatorname{rpoB}(\mathrm{S} 433 \mathrm{~L}$ or $\mathrm{S} 433 \mathrm{P})$ & Rifampicin resistance & Hu et al. (2002) \\
\hline S. lividans & Actinorhodin & $\operatorname{rpoB}(\mathrm{R} 440 \mathrm{C})$ & Using relC mutant & Lai et al. (2002) \\
\hline S. lividans & Actinorhodin & $r p s L(\mathrm{~L} 90 \mathrm{~K}$ or $\mathrm{R} 94 \mathrm{G})$ & Site-directed mutagenesis & Okamoto-Hosoya et al. (2003) \\
\hline S. lividans & Actinorhodin & $r s m G$ & Function-loss mutation & Nishimura et al. (2007) \\
\hline S. lividans & Actinorhodin & cap & Capreomycin resistance & Zhang et al. (2008) \\
\hline S. lividans & Actinorhodin & $\begin{array}{l}r p o B(\mathrm{H} 426 \mathrm{~N} \\
\mathrm{S} 431 \mathrm{~N}, \mathrm{~F} 445 \mathrm{M}, \\
\text { S474Y, M581D) }\end{array}$ & $\begin{array}{l}\text { "Natural" mutant-type } \\
\text { rрoB }\end{array}$ & Tala et al. (2009) \\
\hline S. lividans & Actinorhodin & ery & Erythromycin resistance & Imai et al. (2012) \\
\hline S. antibioticus & Actinomycin & str & Streptomycin resistance & Hosoya et al. (1998) \\
\hline S. antibioticus & Actinomycin & $r s m G$ & Function-loss mutation & Tanaka et al. (2009a) \\
\hline S. antibioticus & Actinomycin & $r p s L(\mathrm{~K} 88 \mathrm{E})$ & Streptomycin resistance & Tanaka et al. (2009a) \\
\hline S. antibioticus & Actinomycin & $r s m G \operatorname{rsp} L(\mathrm{~K} 88 \mathrm{E}$ or $\mathrm{K} 88 \mathrm{R})$ & Double mutation & Tanaka et al. (2009a) \\
\hline S. parvulus & Actinomycin & $r p s L(\mathrm{~K} 88 \mathrm{R})$ & Streptomycin resistance & Tanaka et al. (2009a) \\
\hline S. parvulus & Actinomycin & $r \operatorname{ssm} G$ & Function-loss mutation & Tanaka et al. (2009a) \\
\hline S. parvulus & Actinomycin & ery & Erythromycin resistance & Imai et al. (2012) \\
\hline S. griseus & Streptomycin & $r \operatorname{ssm} G$ & Function-loss mutation & Tanaka et al. (2009b) \\
\hline S. griseus & Streptomycin & ery & Erythromycin resistance & Imai et al. (2012) \\
\hline S. erythraea & Erythromycin & $\operatorname{rps} L(\mathrm{~K} 43 \mathrm{~N})$ & Streptomycin resistance & Tanaka et al. (2009a) \\
\hline S. erythraea & Erythromycin & $r p o B(\mathrm{~S} 444 \mathrm{~F})$ & Rifampicin resistance & Carata et al. (2009) \\
\hline S. albus & Salinomycin & $\operatorname{rps} L(\mathrm{~K} 88 \mathrm{R})$ gen rif & $\begin{array}{l}\text { Triple mutation in an } \\
\text { industrial strain }\end{array}$ & Tamehiro et al. (2003) \\
\hline S. avermitilis & Oligomycin & $\operatorname{rps} L(\mathrm{~K} 43 \mathrm{M}$ or $\mathrm{K} 88 \mathrm{E})$ & Streptomycin resistance & Tanaka et al. (2009a) \\
\hline S. bingchenggensis & Milbemycin & str & Streptomycin resistance & Wang et al. (2009b) \\
\hline S. chattanoogensis & Fredericamycin & str & Streptomycin resistance & Hosoya et al. (1998) \\
\hline S. fradiae & A54145 & $r p s L(\mathrm{~K} 88 \mathrm{R})$ & Streptomycin resistance & Alexander et al. (2010) \\
\hline S. incarnatus & Sinefungin & $r p o B(\mathrm{D} 447 \mathrm{G})$ & Rifampicin resistance & Fukuda et al. (2010) \\
\hline S. lavendulae & Formycin & str & Streptomycin resistance & Hosoya et al. (1998) \\
\hline S. mauvecolor & Piperidamycin & $\begin{array}{l}\text { rpoB }(\mathrm{H} 437 \mathrm{~L}), \text { gen, } \\
\text { or } r p o B \operatorname{rps} L(\mathrm{~K} 88 \mathrm{R})\end{array}$ & Single or double mutation & Hosaka et al. (2009) \\
\hline S. roseosporus & A21978C & $\operatorname{rpsL}(\mathrm{K} 43 \mathrm{~N})$ & Streptomycin resistance & Wang et al. (2012) \\
\hline
\end{tabular}


Table 1 (continued)

\begin{tabular}{|c|c|c|c|c|}
\hline Strain & Antibiotic/enzyme & Mutation & Comment & Reference \\
\hline S. viridochromogenes & Xylanase & $\operatorname{rps} L(\mathrm{~K} 88 \mathrm{R})$ & Streptomycin resistance & Liu et al. (2012) \\
\hline A. orientalis & Norvancomycin & str rif & Double mutation & Wang et al. (2006) \\
\hline P. rosea & GE2270 & str gen rif & $\begin{array}{l}\text { Triple mutation in an } \\
\text { industrial strain }\end{array}$ & Beltrametti et al. (2006) \\
\hline Nonomuraea sp. & Glycopeptide A40926 & $\begin{array}{l}r p o B(\mathrm{H} 426 \mathrm{~N}, \\
\text { S431N, F445M, } \\
\text { S474Y, M581D) }\end{array}$ & "Natural" mutant-type rроB & Vigliotta et al. (2005) \\
\hline Streptomyces sp. & Antibiotics & str & Streptomycin resistance & Hai et al. (2011) \\
\hline Actinomycete & Antitumor activity & str & Streptomycin resistance & Han et al. (2009) \\
\hline Actinomycete & Antitumor activity & str & Streptomycin resistance & Sun et al. (2010) \\
\hline Actinomycete & Antitumor activity & str & Streptomycin resistance & Han et al. (2010) \\
\hline \multicolumn{5}{|l|}{ Eubacteria } \\
\hline E. coli & Cell-free protein synthesis & $r p s L(\mathrm{~K} 87 \mathrm{E})$ & Streptomycin resistance & Hosaka et al. (2004) \\
\hline E. coli & Cell-free protein synthesis & $\operatorname{rps} L(\mathrm{~K} 42 \mathrm{~T})$ & Streptomycin resistance & Chumpolkulwong et al. (2004) \\
\hline E. coli & Replication progression & $\operatorname{rpoB}(\mathrm{H} 447 \mathrm{R})$ & Rifampicin resistance & Baharoglu et al. (2010) \\
\hline E. coli & Violacein & lin kan & $\begin{array}{l}\text { Heterologous } \\
\text { gene expression }\end{array}$ & $\begin{array}{l}\text { Ahmetagic and } \\
\text { Pemberton (2011) }\end{array}$ \\
\hline B. subtilis & Neotrehalosadiamine & $\operatorname{rpoB}(\mathrm{S} 487 \mathrm{~L})$ & Rifampicin resistance & Inaoka et al. (2004) \\
\hline B. subtilis & $\alpha$-Amylase & $r p s L(\mathrm{~K} 56 \mathrm{R})$ & Streptomycin resistance & Kurosawa et al. (2006) \\
\hline B. subtilis & $\begin{array}{l}\text { Sporulation, germination, } \\
\text { competence }\end{array}$ & rрoB(H482R, H482Y) & Rifampicin resistance & Maughan et al. (2004) \\
\hline B. subtilis & Sporulation and tolerance & rров & Rifampicin resistance & Moeller et al. (2012) \\
\hline B. cereus & FR900493 & str & Streptomycin resistance & Hosoya et al. (1998) \\
\hline C. acetobutylicum & Aceton-Butanol & str & Streptomycin resistance & Gao et al. (2012) \\
\hline D. radiodurans & Radiation resistance & $r p o B(\mathrm{~L} 420 \mathrm{R})$ & Rifampicin resistance & Hua et al. (2011) \\
\hline P. luminescens & Nematicidal activity & $r p o B(\mathrm{P} 564 \mathrm{~L})$ & Rifampicin resistance & Qiu et al. (2012) \\
\hline P. putida & 4-HBA resistance & $\begin{array}{r}r p s L(\mathrm{~K} 88 \mathrm{E}) \text { or } \\
r p o B(\mathrm{~S} 517 \mathrm{P})\end{array}$ & $\begin{array}{l}\text { Resistance to } \\
\text { toxic compounds }\end{array}$ & Hosokawa et al. (2002) \\
\hline P. pyrrocinia & Pyrrolnitrin & str & Streptomycin resistance & Hosoya et al. (1998) \\
\hline \multicolumn{5}{|l|}{ Fungi } \\
\hline P. purprogenum & Antitumor activity & gen & Gentamicin resistance & Chai et al. (2012) \\
\hline
\end{tabular}

The genetic symbols, cap, ery, fus, gen, gnt, kan, lin, par, rif, str, and tsp indicate resistance to capreomycin, erythromycin, fusidic acid, gentamicin, geneticin, kanamycin, lincomycin, paromomycin, rifampicin, streptomycin, and thiostrepton, respectively. $r p s L$ and $r p o B$ indicate the genes coding for the ribosomal protein S12 and the RNA polymerase $\beta$-subunit, respectively

\section{Impact on silent gene activation}

Promising approaches for the activation of cryptic biosynthetic gene clusters in Streptomyces species include ribosome engineering; the addition of $\mathrm{N}$-acetylglucosamine to the medium or deletion of the das $R$ gene, which encodes an $N$-acetylglucosamine-responsive regulatory protein, the constitutive overexpression of a pathway-specific large ATP-binding LuxR-type (LAL) regulatory gene, metabolic remodeling, and cell-to-cell interaction. These new approaches may enable the identification of novel and/or poorly understood antibiotics, such as piperidamycin and stambomycin, and are all characterized by applicability to a wide range of actinomycetes and potential scalability to high throughput.
Ribosome engineering

Ribosome engineering is effective for activation of silent genes. For example, among the 1,068 actinomycetes isolated from soil, a fraction of the Streptomyces isolates and most of the non-Streptomyces isolates were found to be nonproducers of antibiotics, with 43 and $6 \%$, respectively, of these nonproducing strains acquiring the ability to synthesize antibacterials against Staphylococcus aureus after a selection step that generated spontaneous $r p s L$ or $r p o B$ mutations (Hosaka et al. 2009). Assessment of Streptomyces mauvecolor 631689, a strain that produced no antibacterial activity in any medium tested, demonstrated that two rpoB mutants (H437D or H437L), a double mutant of rpoB (H437L) and rpsL (K88R), and a gentamicin-resistant (GenR) mutant 
produced a family of antibiotics, the piperidamycins (Fig. 1). The activation of silent genes by the rpoB H437D or H437L mutations was attributed, at least in part, to the increased affinity of mutant RNAP for the silent gene promoters (Hosaka et al. 2009).

Species of Bacillus produce a variety of commercially important metabolites and extracellular enzymes. The introduction of the rpoB mutation $\mathrm{S} 487 \mathrm{~L}$ into a Bacillus subtilis strain resulted in cells that overproduced an aminosugar antibiotic, 3,3'-neotrehalosadiamine (NTD), the production of which is dormant in the wild-type strain (Inaoka et al. 2004). Perhaps, unlike the wild-type RNAP, the mutant RNAP efficiently recognized the $\sigma^{\mathrm{A}}$-dependent promoters, resulting in the dramatic activation of the NTD biosynthesis pathway. Although most of the work was performed using S. lividans, we have now demonstrated that $r p o B$ mutations are widely effective in activating silent and poorly expressed secondary metabolite-biosynthetic gene clusters at the transcriptional level in Streptomyces griseus (up to 70-fold activation), S. coelicolor (up to eightfold activation), and $S$. erythraea (up to sevenfold activation; Tanaka and Ochi, manuscript in preparation). Notably, the activation of silent gene clusters by $r р о B$ mutations was medium-dependent, with each $r p o B$ mutation exerting differential effects on the activation of each silent gene cluster. These findings suggest that strains containing rров mutations (e.g., H437Y, H437R) should be grown in different media to assess the full spectrum of silent gene activation.

The recent observation, that several actinomycetes possess two rpoB genes (Vigliotta et al. 2005), has suggested a new strategy of activating silent gene expression in bacteria. Two rроB paralogs, rроB(S) and rроB(R), provide Nonomuraea sp. strain 39727 with two functionally distinct and developmentally regulated RNAPs. The product of $\operatorname{rpo} B(R)$, the expression of which increases after transition to stationary phase, is characterized by five amino acid substitutions (H426N, S431N, F445M, S474Y, and M581D) located within or close to the rifampicin resistance cluster. The expression of $r p o B(R)$ was found to markedly activate antibiotic biosynthesis, with the $\operatorname{rpoB}(R)$-specific $\mathrm{H} 426 \mathrm{~N}$ mutation found essential in activating secondary metabolism (Tala et al. 2009). Additional rif cluster-associated rpoB $(R)$-specific missense mutations likely interact functionally with the $\mathrm{H} 426 \mathrm{~N}$ mutation, leading to the marked effect of $r p o B(R)$. Mutant type, or duplicated, $r p o B$ often exists in nature, with rpoB gene polymorphisms detected in five of 75 inherently rifampicin-resistant actinomycetes isolated from nature, although these polymorphisms were preferentially distributed in the so-called rare actinomycetes, not in Streptomyces spp. Notably, all but one of these rifampicin-resistant rare actinomycete isolates obtained to date were able to produce antibiotics (Tala et al. 2009).

From a practical viewpoint, these findings suggest the intriguing possibility of using $r p o B(R)$-based technology to improve strains and to search for novel bioactive molecules by activating silent genes. This technology should have greater potential than the simple rif selection currently used to improve the production of secondary metabolites, as the introduction of $r p o B(R)$ enhanced antibiotic production eightfold when compared with the introduction of the H426Y mutation (Tala et al. 2009). It is also of interest to examine whether various $\operatorname{rpo} B(R)$ forms found in nature are more capable of activating silent bacterial genes than Nonomuraea $\operatorname{rpo} B(R)$. Thus, understanding the status of natural $r p o B(R)$ and utilizing it for cryptic gene activation may provide new horizons for medical and industrial microbiology.

\section{das $R-N$-acetylglucosamine system}

DasR is a global regulator of antibiotic biosynthesis, which links nutrient stress to antibiotic production by Streptomyces (van Wezel and McDowall 2011). $N$-acetylglucosamine (GlcNAc), a major component of the cell walls of fungi, is the second most abundant polysaccharide in nature. A high concentration of GlcNAc, perhaps mimicking its accumulation after autolytic degradation of the vegetative mycelium, may be a major checkpoint for the onset of secondary metabolism (Rigali et al. 2008). The response is transmitted to antibiotic pathway-specific activators through the pleiotropic transcriptional repressor DasR, suggesting a new strategy for activating pathways of secondary metabolite biosynthesis. In S. coelicolor, GlcNAc $(\sim 10 \mathrm{mM})$ blocks development and antibiotic production under rich growth conditions, but triggers antibiotic production and sporulation under poor nutritional conditions (i.e., minimal medium), suggesting that the effect of GlcNAc depends on the specific culture conditions. GlcNAc also stimulated antibiotic production by other Streptomyces spp., including Streptomyces clavuligerus,
Fig. 1 Detection of antibacterial compounds produced by drugresistant mutants of $S$. mauvecolor 631689. a HPLC profiles of culture extracts. The arrows $(A-H)$ indicate the bioactive fractions. b The chemical structures of the antibacterial compounds isolated
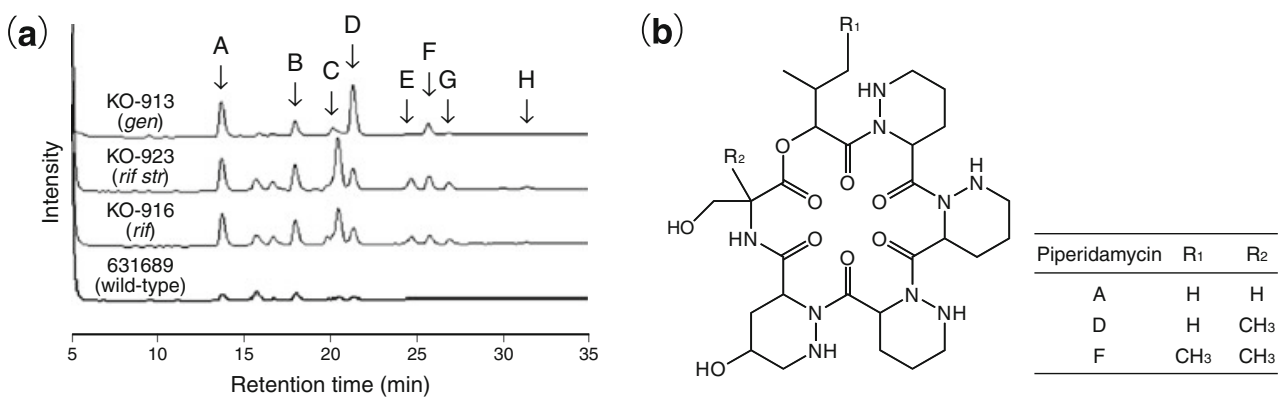
Streptomyces collonus, S. griseus, Streptomyces hygroscopicus, and Streptomyces venezuelae (Rigali et al. 2008).

The GlcNAc regulon is controlled by the GntR regulator DasR, the DNA-binding activity of which is inhibited by glucosamine-6-phosphate. Introduction of mutations into das $R$ effectively enhanced antibiotic productivity. For example, the $S$. coelicolor dasR mutant BAP29 showed three- to fourfold enhanced and accelerated production of pigmented antibiotics (Rigali et al. 2008). The position of the DasR binding site in the act II-ORF4 promoter indicates that DasR represses transcription of this gene. Interestingly, the dasR mutant BAP29 was found to be awakened for cryptic gene clusters encoding a hypothetical antibiotic made by a type I modular polyketide synthase (SCO6273-6288), showing that this method is applicable for activating silent gene clusters (Rigali et al. 2008).

\section{LAL regulatory system}

Constitutive overexpression of a putative pathway-specific LAL regulator was shown to successfully induce the expression of the silent type I modular polyketide synthase (PKS) gene cluster in Streptomyces ambofaciens 23877, enabling the identification of a unique structural class of polyketides with promising antitumor activity (Laureti et al. 2011). S. ambofaciens 23877 produces two antibiotics, the macrolide spiramycin and the pyrrole-amide congocidine. Sequence analysis of its genome showed that $S$. ambofaciens 23877 contains several secondary metabolite biosynthetic gene clusters, including a giant type I modular PKS gene cluster. This cluster is composed of 25 genes, nine of which encode PKSs, and spans almost $150 \mathrm{~kb}$, making it one of the largest polyketide biosynthetic gene clusters described to date. The metabolic product(s) of this gene cluster have not been determined and transcriptional analyses showed that this cluster is not expressed under laboratory growth conditions. The constitutive expression of a regulatory gene within this cluster, encoding a protein that is similar to the LAL family of proteins, triggered the expression of the biosynthetic genes. This led to the identification of four 51-membered glycosylated macrolides, named stambomycins A-D, as metabolic products of the gene cluster (Laureti et al. 2011). Database searches have identified genes that encode LAL regulators within numerous cryptic biosynthetic gene clusters in actinomycete genomes, for which metabolic product(s) remain to be discovered, suggesting that constitutive expression of such pathway-specific activators represents a powerful approach for the discovery of novel bioactive natural products.

The metabolism-remodeling approach

Although activation of biosynthetic genes at the transcriptional level is primarily important for exploiting useful metabolites, perturbation of biosynthesis by modulating, for example, the supply of precursors may also be a promising approach to enhancing the cell's capability to produce secondary metabolites, a process termed metabolic engineering (Olano et al. 2008). One method of enhancing the yields of secondary metabolites consists of modulating fatty acid biosynthesis using small molecules. For example, screening of a large number $(>30,000)$ of small molecules, seeking candidates that might "remodel" the yields of actinorhodin in $S$. coelicolor, identified 19 compounds that caused elevated or precocious production of actinorhodin (Craney et al. 2012). Further examination of four of these 19 molecules, antibiotic remodeling compounds (ARC)2, 3, 4, and 5, showed that (1) low concentrations of ARC2 enhanced the yield of actinorhodin, (2) the ARC2 effect can be observed in other actinomycetes, suggesting that the molecular target and mechanism of ARC2 is conserved in various actinomycetes, and (3) several of the most active molecules are structurally similar to the known antimicrobial agent triclosan, an inhibitor of fatty acid synthesis. The ARC2 effects therefore involve the inhibition of the enoyl reductase activity of FabI, an enzyme that catalyzes the final and rate-limiting step in fatty acid biosynthesis. Since fatty acid and polyketide synthesis share the precursors acetyl-CoA and malonyl-CoA, partial inhibition of fatty acid synthesis could recruit those acyl-CoAs preferentially to polyketide biosynthesis.

The ARC2 series of molecules not only enhanced the yields of known antibiotics, but induced the production of as yet unidentified compounds in Streptomyces peuceticus, compounds that could not be detected in the absence of ARC2 (Craney et al. 2012). Conceivably, the expression levels of the genes encoding the enzymes to synthesize these compounds are very low (i.e., nearly but not entirely silent), so that reinforcement of the biosynthetic process by an efficient supply of substrate made possible their detection. Alternatively, some other yet-unknown mechanism may be involved in the observed phenomenon. Theoretically, this approach may be enhanced by combination with the transcription-associated approaches (Ochi and Okamoto 2012). It may be possible to develop similar approaches for other classes of antibiotics, such as aminoglycosides and nonribosomal peptides, to access the full spectrum of secondary metabolites.

\section{Approach from cell-to-cell interactions}

Co-culture is an effective method of inducing the production of cryptic metabolites. Although some co-culture methods have been reported, these methods are often specific to two bacterial strains. This limitation may be overcome by a novel fermentation method, the combined culture method, involving the co-culture of two bacterial strains (Onaka et al. 2011). Mycolic acid-containing bacteria could influence the biosynthesis of cryptic natural products in Streptomyces spp. The production of red pigment by S. lividans was induced 
by co-culture with Tsukamurella pulmonis, a mycolic acidcontaining bacterium. Importantly, co-culture with T. pulmonis improved or inhibited natural product biosynthesis in $88 \%$ of the Streptomyces strains isolated from soil: the production of new secondary metabolites was detected in $37 \%$ of strains, while increased metabolite production was detected in $55 \%$ of strains. The other mycolic acid-containing bacteria, Rhodococcus erythropolis and Corynebacterium glutamicum, improved or inhibited biosynthesis in 87 and $90 \%$ of the Streptomyces strains, respectively: the production of new secondary metabolites was detected in 32 and $24 \%$ of strains, respectively. Co-culture of T. pulmonis with Streptomyces endus led to the identification of a novel antibiotic, alchivemycin A. The addition of mycolic acid into the medium of pure $S$. lividans cultures had no effect on antibiotic production, suggesting that mycolic acid localized to the outer cell layer of the inducer bacterium affected secondary metabolism in Streptomyces, with this activity resulting from the direct cell-to-cell interaction of the two bacterial strains (Onaka et al. 2011). This method is also scalable for inducing the production of cryptic antibiotics, as it only involves the addition of a mycolic acid-containing bacterium to a pure culture of an actinomycete.

\section{Applicability of ribosome engineering to myxobacteria}

Interest in myxobacteria, an important source of novel classes of secondary metabolites, has increased. The genomes of myxobacteria are large $(9.14 \mathrm{Mb}$ in Myxococcus xanthus and $13.03 \mathrm{Mb}$ in Sorangium cellulosum), similar or larger than the genome of $S$. coelicolor $(8.67 \mathrm{Mb})$. Myxobacterial genomes have been found to encode many genes involved in the synthesis of secondary metabolites (e.g., $8.6 \%$ of the M. xanthus genome), opening the possibility of discovering clinically relevant natural products (Goldman et al. 2006; Schneiker et al. 2007; Wenzel and Muller 2009). Of the myxobacteria, the genus Sorangium is particularly valuable, as $46 \%$ of metabolites isolated from myxobacteria are derived from this genus. Most myxobacterial metabolites are polyketides, nonribosomal peptides, and hybrids of the two structures. Hence, activation or enhancement of cryptic genes in the genus Sorangium is of interest, and the strategy of ribosome engineering may be utilized successfully for drug discovery.

\section{Applicability of ribosome engineering to eukaryotes}

Fungi have been among the most important sources of biologically active secondary metabolites. Following the publication of the complete genome sequence of the model yeast Saccharomyces cerevisiae (Goffeau et al. 1996), hundreds of fungal genome projects have been carried out worldwide. As a result, large numbers of fungal genome sequences are now available publicly, including those of well-known producers of secondary metabolites, such as Aspergillus oryzae and Penicillium chrysogenum (Ma and Fedorova 2010). Their genomes, like those of Streptomyces, are also enriched in genes involved in secondary metabolite biosynthesis. Similar to Streptomyces, however, most biosynthetic gene clusters in fungi are either silent or expressed at very low levels under laboratory conditions. Thus, understanding the physiological conditions under which these genes are activated and developing a pragmatic approach for utilizing such genetic potential is important. A simple and yet efficient approach to isolate more secondary metabolites by exploring the genetic potential in fungi is to vary easily accessible cultivation parameters (Bode et al. 2002). Alternatively, physiological interaction among microorganisms may be practical. For example, cocultivation of Aspergillus nidulans and Streptomyces rapamycinicus selectively stimulated cryptic fungal gene clusters involved in the biosynthesis of secondary metabolites, such as orsellinic acid, lecanoric acid, and the cathepsin $\mathrm{K}$ inhibitors F-9775A and F-9775B (Schroeckh et al. 2009). Small molecule epigenetic modifiers, such as the DNA methyltransferase inhibitor 5-azacytidine and the histone deacetylase inhibitor suberoylanilide hydroxamic acid, have been shown effective not only in altering secondary metabolite profiles but in generating new biomolecules (Williams et al. 2008). Likewise, nucleoid structure may be playing an analogous role to fungal chromatin structure in controlling transcriptional programs in actinomycetes, thus Moore et al. (2012) reported chemical elicitors that stimulate biosynthetic gene clusters in Streptomyces.

The concept based on bacterial ribosome engineering, as described above, has been applied to fungi to produce secondary metabolites. For example, introduction of gentamicin resistance into the marine-derived fungal strain Penicillium purpurogenum G59 effectively activated silent gene clusters for secondary metabolites (Chai et al. 2012). Although gentamicin did not inhibit this strain G59 during routine testing, treatment of G59 spores with high concentrations of gentamicin, in combination with dimethyl sulfoxide, inhibited strain growth, allowing the development of gentamicin-resistant colonies on agar plate. This method produced four antitumor secondary metabolites not found in the secondary metabolites of other $P$. purpurogenum strains. In addition, hygromycin B-resistant mutants of Monascus pilosus NBRC 4520 that exhibited enhanced production of secondary metabolites could be isolated using the general method used to obtain drug-resistant mutants in bacteria (Hosaka and Mizukami, unpublished data), because hygromycin B is an aminoglycoside antibiotic that potently inhibits protein synthesis in both prokaryotic and eukaryotic cells (Gonzalez et al. 1978). These findings indicate that 
modulation of ribosomal function may be applicable to a variety of fungi to elicit their potential secondary metabolism.

A new insight into the silent gene activation in the eukaryotic microorganisms is also coming from the ectopic ppGpp expression. The bacterial alarmone ppGpp, produced by RelA-SpoT homologue (RelA or RSH) on the ribosome in response to nutrient limitation, is a key signal factor to initiate the onset of bacterial secondary metabolism (Bibb 2005; Ochi 2007). Although relA and $R S H$, the genes encoding ppGpp synthetase, are distributed widely in bacteria and plants (Givens et al. 2004; Takahashi et al. 2004; Tozawa and Nomura 2011; van der Biezen et al. 2000), neither of these genes, nor ppGpp itself, has yet been identified in animals or eukaryotic microorganisms. Despite the essential lack of a relA-spoT homologue and ppGpp in the yeast $S$. cerevisiae, its heterologous expression of a relA-spoT homologue ( $\mathrm{Sj}$ $R S H$ ) isolated from the halophilic plant Suaeda japonica resulted in the accumulation of ppGpp, accompanied by the enhancement of tolerance against various stressors, including osmotic stress, ethanol, and freezing (Ochi et al. 2012; Yamada et al. 2003). Low levels of ppGpp [10-20 pmol (mg dry weight $)^{-1}$ ] were sufficient for cellular stress tolerance without affecting growth rate (Ochi et al. 2012). These results raise an intriguing possibility that the ppGpp system can be applicable to the silent gene activation in such eukaryotic microorganisms as fungi.

\section{Applicability of rare earth elements to biotechnology}

Despite the importance of rare earth elements (REEs) in the chemical industry, little is known about their biological effects in living cells. These elements, however, have recently been shown involved in the overproduction of antibiotics and in the activation of silent or poorly expressed genes in bacteria. The REEs consist of 17 elements, including scandium, yttrium, and the lanthanides (i.e., the 15 elements from lanthanum (La) to lutetium in the periodic table). Low concentrations (10$100 \mu \mathrm{M}$ ) of scandium (Sc) added to cultures of S. coelicolor (an actinorhodin producer), Streptomyces antibioticus (an actinomycin producer), and S. griseus (a streptomycin producer) were found to enhance antibiotic production 2-25-fold (Kawai et al. 2007). The effects of Sc were exerted at the level of transcription of pathway-specific positive regulatory genes, as demonstrated by marked upregulation of act II-ORF4 in $S$. coelicolor. Notably, REEs were effective in activating silent and poorly expressed secondary metabolite biosynthetic genes in Streptomyces. That is, the addition to the medium of low concentrations of Sc or La activated the expression of nine genes, 2.5 - to 12 -fold, belonging to nine secondary metabolite-biosynthetic gene clusters of $S$. coelicolor (Tanaka et al. 2010). HPLC analysis of ethyl acetate-extractable metabolites indicated that several compounds could be detected only in the REE-treated cultures. This approach, due to its feasibility, should facilitate the discovery of new biologically active compounds. The ability of REEs (especially Sc) to enhance enzyme production and secondary metabolism was also observed in $B$. subtilis. The addition of Sc to the growth medium stimulated the production of both $\alpha$-amylase and bacilysin at the transcriptional level (Inaoka and Ochi 2011).

REEs have long been known to have weak antimicrobial potency. Thus, it was possible to develop Sc-resistant mutants on plates containing Sc. As expected, actinorhodin overproducers (Ochi, unpublished results) and $\alpha$-amylase overproducers (Inaoka and Ochi 2012) were often found among the mutants of $S$. coelicolor and B. subtilis, respectively. In $B$. subtilis, a mutation in the uppS gene, which encodes the enzyme undecaprenyl pyrophosphate synthase, was responsible for the Sc resistance phenotype and $\alpha$-amylase overproduction. This uppS86 mutation, however, did not affect the levels of amyE expression, suggesting that this mutation exerted its effects at the post-transcriptional level (Inaoka and Ochi 2012). Thus, the mechanism by which $\alpha$-amylase production was stimulated by the uppS86 mutation differed from that caused by the addition of Sc to the growth medium.

An important advantage of using REEs is that this method does not require any gene engineering technology or genomic information on the strains examined. Since REEs are distributed ubiquitously throughout the world, it is conceivable that microorganisms have acquired the ability to respond to low levels of these elements over the course of their long evolutionary history, possibly as a means of adapting their physiology to prevailing conditions. The effect of low concentrations of $\mathrm{Sc}$ on antibiotic production indicates that Sc functions in situ as a factor that induces or stimulates the production of secondary metabolites, including pigments, mycotoxins, phytotoxins, and antibiotics. "Rare earth microbiology" may thus offer new insight into entirely unknown regulatory events that occur in all organisms.

\section{Concluding remarks}

The availability of genome sequence information on various microorganisms and newly developed methods of activating silent and poorly expressed genes suggest that natural product research has now entered a promising new era. Particular attention should be paid to combined approaches that include the transcription activation of key genes and metabolism remodeling. Reinforcement of biosynthetic processes by efficient substrate supply may be synergistic with transcription activation, eventually leading to the efficient discovery of new secondary metabolites. Another point of interest is the application of ribosome engineering to activate the silent biosynthetic pathways in fungi and myxobacteria, which may result 
in the efficient exploitation of novel secondary metabolites of these microbial groups. Also, since ppGpp enhances yeast cell tolerance to various stress stimuli, the ability of ectopic ppGpp in fungal cells to induce the synthesis of novel secondary metabolites is of interest. Apart from the technology, it would be important to envisage the reason why cryptic genes are silent in the laboratory fermentation conditions. Are the silent genes expressed under the special yet-unknown environmental conditions? If so, do the cryptic secondary metabolites play an intrinsic biological role(s) for producing organisms under the special environmental conditions? What are such special environmental conditions, if any? Understanding the mechanism(s) underlying the silencing of cryptic genes would help to fully untilize the microbial gene clusters for secondary metabolism.

Acknowledgments The work of ribosome engineering was supported mainly by grants from the Monka-sho of the Japanese government and the Programme for Promotion of Basic and Applied Researches for Innovations in Bio-oriented Industry. We are grateful to Drs. Susumu Okamoto and Yukinori Tanaka for valuable advice in preparing this manuscript.

Open Access This article is distributed under the terms of the Creative Commons Attribution License which permits any use, distribution, and reproduction in any medium, provided the original author(s) and the source are credited.

\section{References}

Ahmetagic A, Pemberton JM (2011) Antibiotic resistant mutants of Escherichia coli K12 show increases in heterologous gene expression. Plasmid 65:51-57

Alexander DC, Rock J, He X, Brian P, Miao V, Baltz RH (2010) Development of a genetic system for combinatorial biosynthesis of lipopeptides in Streptomyces fradiae and heterologous expression of the A54145 biosynthesis gene cluster. Appl Environ Microbiol 76:6877-6887

Artsimovitch I, Patlan V, Sekine S, Vassylyeva MN, Hosaka T, Ochi K, Yokoyama S, Vassylyev DG (2004) Structural basis for transcription regulation by alarmone ppGpp. Cell 117:299-310

Baharoglu Z, Lestini R, Duigou S, Michel B (2010) RNA polymerase mutations that facilitate replication progression in the rep uvrD $r e c F$ mutant lacking two accessory replicative helicases. Mol Microbiol 77:324-336

Baltz RH (2010) Streptomyces and Saccharopolyspora hosts for heterologous expression of secondary metabolite gene clusters. J Ind Microbiol Biotechnol 37:759-772

Baltz RH (2011) Strain improvement in actinomycetes in the postgenomic era. J Ind Microbiol Biotechnol 38:657-666

Beltrametti F, Rossi R, Selva E, Marinelli F (2006) Antibiotic production improvement in the rare actinomycete Planobispora rosea by selection of mutants resistant to the aminoglycosides streptomycin and gentamycin and to rifamycin. J Ind Microbiol Biotechnol $33: 283-288$

Bentley SD, Chater KF, Cerdeno-Tarraga AM, Challis GL, Thomson NR, James KD, Harris DE, Quail MA, Kieser H, Harper D, Bateman A, Brown S, Chandra G, Chen CW, Collins M, Cronin A, Fraser A, Goble A, Hidalgo J, Hornsby T, Howarth S, Huang CH, Kieser T, Larke L, Murphy L, Oliver K, O’Neil S, Rabbinowitsch E,
Rajandream MA, Rutherford K, Rutter S, Seeger K, Saunders D, Sharp S, Squares R, Squares S, Taylor K, Warren T, Wietzorrek A, Woodward J, Barrell BG, Parkhill J, Hopwood DA (2002) Complete genome sequence of the model actinomycete Streptomyces coelicolor A3(2). Nature 417:141-147

Bibb MJ (2005) Regulation of secondary metabolism in streptomycetes. Curr Opin Microbiol 8:208-215

Bode HB, Bethe B, Hofs R, Zeeck A (2002) Big effects from small changes: possible ways to explore nature's chemical diversity. Chembiochem 3:619-627

Carata E, Peano C, Tredici SM, Ferrari F, Tala A, Corti G, Bicciato S, De Bellis G, Alifano P (2009) Phenotypes and gene expression profiles of Saccharopolyspora erythraea rifampicin-resistant (rif) mutants affected in erythromycin production. Microb Cell Fact $8: 18-32$

Chai YJ, Cui CB, Li CW, Wu CJ, Tian CK, Hua W (2012) Activation of the dormant secondary metabolite production by introducing gentamicin-resistance in a marine-derived Penicillium purpurogenum G59. Mar Drugs 10:559-582

Chiang YM, Chang SL, Oakley BR, Wang CC (2011) Recent advances in awakening silent biosynthetic gene clusters and linking orphan clusters to natural products in microorganisms. Curr Opin Chem Biol 15:137-143

Chumpolkulwong N, Hori-Takemoto C, Hosaka T, Inaoka T, Kigawa T, Shirouzu M, Ochi K, Yokoyama S (2004) Effects of Escherichia coli ribosomal protein S12 mutations on cell-free protein synthesis. Eur J Biochem 271:1127-1134

Craney A, Ozimok C, Pimentel-Elardo SM, Capretta A, Nodwell JR (2012) Chemical perturbation of secondary metabolism demonstrates important links to primary metabolism. Chem Biol 19:1020-1027

Fukuda K, Tamura T, Ito H, Yamamoto S, Ochi K, Inagaki K (2010) Production improvement of antifungal, antitrypanosomal nucleoside sinefungin by $г$ гов mutation and optimization of resting cell system of Streptomyces incarnatus NRRL 8089. J Biosci Bioeng 109:459-465

Gao X, Zhao H, Zhang G, He K, Jin Y (2012) Genome shuffling of Clostridium acetobutylicum CICC 8012 for improved production of acetone-butanol-ethanol (ABE). Curr Microbiol 65:128-132

Givens RM, Lin MH, Taylor DJ, Mechold U, Berry JO, Hernandez VJ (2004) Inducible expression, enzymatic activity, and origin of higher plant homologues of bacterial RelA/SpoT stress proteins in Nicotiana tabacum. J Biol Chem 279:7495-7504

Goffeau A, Barrell BG, Bussey H, Davis RW, Dujon B, Feldmann H, Galibert F, Hoheisel JD, Jacq C, Johnston M, Louis EJ, Mewes HW, Murakami Y, Philippsen P, Tettelin H, Oliver SG (1996) Life with 6000 genes. Science 274(546):563-547

Goldman BS, Nierman WC, Kaiser D, Slater SC, Durkin AS, Eisen JA, Ronning CM, Barbazuk WB, Blanchard M, Field C, Halling C, Hinkle G, Iartchuk O, Kim HS, Mackenzie C, Madupu R, Miller N, Shvartsbeyn A, Sullivan SA, Vaudin M, Wiegand R, Kaplan HB (2006) Evolution of sensory complexity recorded in a myxobacterial genome. Proc Natl Acad Sci USA 103:15200-15205

Gomez-Escribano JP, Bibb MJ (2011) Engineering Streptomyces coelicolor for heterologous expression of secondary metabolite gene clusters. Microb Biotechnol 4:207-215

Gonzalez A, Jimenez A, Vazquez D, Davies JE, Schindler D (1978) Studies on the mode of action of hygromycin B, an inhibitor of translocation in eukaryotes. Biochim Biophys Acta 521:459-469

Hai L, Huang Y, Liao G, Hu C (2011) Ribosome engineering of Streptomyces sp. FJ3 from Three Gorges reservoir area and metabolic product of the selected mutant strain. Wei Sheng Wu Xue Bao 51:934-940

Han X, Cui C, Han X, Li C, Yang M (2009) Alteration of metabolic function of wild-type actinomycete strain by ribosome engineering and the metabolites newly produced with antitumor activity. $\mathrm{J}$ Int Pharma Res 36:435-442 
Han X, Cui C, Yao Z, Yang M (2010) The alteration of secondary metabolism of actinomycetes from terrestrial and marine environments by ribosome-engineering. Period Ocean Univ China 40:47-52

Hesketh A, Ochi K (1997) A novel method for improving Streptomyces coelicolor A3(2) for production of actinorhodin by introduction of $r p s L$ (encoding ribosomal protein S12) mutations conferring resistance to streptomycin. J Antibiot (Tokyo) 50:532535

Hosaka T, Ohnishi-Kameyama M, Muramatsu H, Murakami K, Tsurumi Y, Kodani S, Yoshida M, Fujie A, Ochi K (2009) Antibacterial discovery in actinomycetes strains with mutations in RNA polymerase or ribosomal protein S12. Nat Biotechnol 27:462-464

Hosaka T, Tamehiro N, Chumpolkulwong N, Hori-Takemoto C, Shirouzu M, Yokoyama S, Ochi K (2004) The novel mutation $\mathrm{K} 87 \mathrm{E}$ in ribosomal protein $\mathrm{S} 12$ enhances protein synthesis activity during the late growth phase in Escherichia coli. Mol Genet Genomics 271:317-324

Hosaka T, Xu J, Ochi K (2006) Increased expression of ribosome recycling factor is responsible for the enhanced protein synthesis during the late growth phase in an antibiotic-overproducing Streptomyces coelicolor ribosomal rpsL mutant. Mol Microbiol 61:883-897

Hosokawa K, Park NH, Inaoka T, Itoh Y, Ochi K (2002) Streptomycinresistant $(r p s L)$ or rifampicin-resistant $(r p o B)$ mutation in Pseudomonas putida KH146-2 confers enhanced tolerance to organic chemicals. Environ Microbiol 4:703-712

Hosoya Y, Okamoto S, Muramatsu H, Ochi K (1998) Acquisition of certain streptomycin-resistant (str) mutations enhances antibiotic production in bacteria. Antimicrob Agents Chemother 42:2041-2047

$\mathrm{Hu} \mathrm{H}$, Ochi K (2001) Novel approach for improving the productivity of antibiotic-producing strains by inducing combined resistant mutations. Appl Environ Microbiol 67:1885-1892

Hu H, Zhang Q, Ochi K (2002) Activation of antibiotic biosynthesis by specified mutations in the rpoB gene (encoding the RNA polymerase $\beta$-subunit) of Streptomyces lividans. J Bacteriol 184:3984-3991

Hua XT, Wang H, Wang C, Tian B, Hua YJ (2011) Global effect of an RNA polymerase $\beta$-subunit mutation on gene expression in the radiation-resistant bacterium Deinococcus radiodurans. Sci China Life Sci 54:854-862

Huh JH, Kim DJ, Zhao XQ, Li M, Jo YY, Yoon TM, Shin SK, Yong JH, Ryu YW, Yang YY, Suh JW (2004) Widespread activation of antibiotic biosynthesis by $S$-adenosylmethionine in streptomycetes. FEMS Microbiol Lett 238:439-447

Ikeda H, Ishikawa J, Hanamoto A, Shinose M, Kikuchi H, Shiba T, Sakaki Y, Hattori M, Omura S (2003) Complete genome sequence and comparative analysis of the industrial microorganism Streptomyces avermitilis. Nat Biotechnol 21:526-531

Imai Y, Fujiwara T, Ochi K, Hosaka T (2012) Development of the ability to produce secondary metabolites in Streptomyces through the acquisition of erythromycin resistance. J Antibiot (Tokyo) 65:323-326

Inaoka T, Ochi K (2011) Scandium stimulates the production of amylase and bacilysin in Bacillus subtilis. Appl Environ Microbiol $77: 8181-8183$

Inaoka T, Ochi K (2012) Undecaprenyl pyrophosphate involvement in susceptibility of Bacillus subtilis to rare earth elements. J Bacteriol 194:5632-5637

Inaoka T, Takahashi K, Yada H, Yoshida M, Ochi K (2004) RNA polymerase mutation activates the production of a dormant antibiotic 3,3'-neotrehalosadiamine via an autoinduction mechanism in Bacillus subtilis. J Biol Chem 279:3885-3892

Kawai K, Wang G, Okamoto S, Ochi K (2007) The rare earth, scandium, causes antibiotic overproduction in Streptomyces spp. FEMS Microbiol Lett 274:311-315
Kim DJ, Huh JH, Yang YY, Kang CM, Lee IH, Hyun CG, Hong SK, Suh JW (2003) Accumulation of $S$-adenosyl-L-methionine enhances production of actinorhodin but inhibits sporulation in Streptomyces lividans TK23. J Bacteriol 185:592-600

Komatsu M, Komatsu K, Koiwai H, Kosone I, Izumikawa M, Hashimoto J, Takagi M, Shin-ya K, Cane DE, Ikeda H (2013) Engineered Streptomyces avermitilis host for heterologous expression of biosynthetic gene cluster for secondary metabolites. ACS Synthet Biol (in press)

Komatsu M, Uchiyama T, Omura S, Cane DE, Ikeda H (2010) Genome-minimized Streptomyces host for the heterologous expression of secondary metabolism. Proc Natl Acad Sci USA 107:2646-2651

Kurosawa K, Hosaka T, Tamehiro N, Inaoka T, Ochi K (2006) Improvement of $\alpha$-amylase production by modulation of ribosomal component protein S12 in Bacillus subtilis 168. Appl Environ Microbiol 72:71-77

Lai C, Xu J, Tozawa Y, Okamoto-Hosoya Y, Yao X, Ochi K (2002) Genetic and physiological characterization of $r p o B$ mutations that activate antibiotic production in Streptomyces lividans. Microbiology $148: 3365-3373$

Laureti L, Song L, Huang S, Corre C, Leblond P, Challis GL, Aigle B (2011) Identification of a bioactive 51-membered macrolide complex by activation of a silent polyketide synthase in Streptomyces ambofaciens. Proc Natl Acad Sci USA 108:6258-6263

Li L, Guo J, Wen Y, Chen Z, Song Y, Li J (2010) Overexpression of ribosome recycling factor causes increased production of avermectin in Streptomyces avermitilis strains. J Ind Microbiol Biotechnol 37:673-679

Liu Z, Zhao X, Bai F (2012) Production of xylanase by an alkalinetolerant marine-derived Streptomyces viridochromogenes strain and improvement by ribosome engineering. Appl Microbiol Biotechnol. doi:10.1007/s00253-012-4290-y

Ma LJ, Fedorova ND (2010) A practical guide to fungal genome projects: strategy, technology, cost and completion. Mycology: An International Journal on Fungal Biology 1:9-24

Maharjan S, Koju D, Lee HC, Yoo JC, Sohng JK (2012) Metabolic engineering of Nocardia sp. CS682 for enhanced production of nargenicin A(1). Appl Biochem Biotechnol 166:805-817

Maharjan S, Oh TJ, Lee HC, Sohng JK (2008) Heterologous expression of metK1-sp and afsR-sp in Streptomyces venezuelae for the production of pikromycin. Biotechnol Lett 30:1621-1626

Maughan H, Galeano B, Nicholson WL (2004) Novel rpoB mutations conferring rifampin resistance on Bacillus subtilis: global effects on growth, competence, sporulation, and germination. J Bacteriol 186:2481-2486

Moeller R, Vlasic I, Reitz G, Nicholson WL (2012) Role of altered rpoB alleles in Bacillus subtilis sporulation and spore resistance to heat, hydrogen peroxide, formaldehyde, and glutaraldehyde. Arch Microbiol 194:759-767

Moore JM, Bradshaw E, Seipke RF, Hutchings MI, McArthur M (2012) Use and discovery of chemical elicitors that stimulate biosynthetic gene clusters in Streptomyces bacteria. Methods Enzymol 517:367-385

Nishimura K, Hosaka T, Tokuyama S, Okamoto S, Ochi K (2007) Mutations in $r s m G$, encoding a $16 \mathrm{~S}$ rRNA methyltransferase, result in low-level streptomycin resistance and antibiotic overproduction in Streptomyces coelicolor A3(2). J Bacteriol 189:38763883

Nodwell JR (2007) Novel links between antibiotic resistance and antibiotic production. J Bacteriol 189:3683-3685

Ochi K (2007) From microbial differentiation to ribosome engineering. Biosci Biotechnol Biochem 71:1373-1386

Ochi K, Kim JY, Tanaka Y, Wang G, Masuda K, Nanamiya H, Okamoto S, Tokuyama S, Adachi Y, Kawamura F (2009) Inactivation of $K s g A$, a $16 \mathrm{~S}$ rRNA methyltransferase, causes vigorous emergence 
of mutants with high-level kasugamycin resistance. Antimicrob Agents Chemother 53:193-201

Ochi K, Nishizawa T, Inaoka T, Yamada A, Hashimoto K, Hosaka T, Okamoto S, Ozeki Y (2012) Heterologous expression of a plant RelA-SpoT homologue results in increased stress tolerance in Saccharomyces cerevisiae by accumulation of the bacterial alarmone ppGpp. Microbiology 158:2213-2224

Ochi K, Okamoto S (2012) A magic bullet for antibiotic discovery. Chem Biol 19:932-934

Ochi K, Okamoto S, Tozawa Y, Inaoka T, Hosaka T, Xu J, Kurosawa K (2004) Ribosome engineering and secondary metabolite production. Adv Appl Microbiol 56:155-184

Ochi K, Zhang D, Kawamoto S, Hesketh A (1997) Molecular and functional analysis of the ribosomal L11 and S12 protein genes (rplK and rpsL) of Streptomyces coelicolor A3(2). Mol Gen Genet 256:488-498

Oh TJ, Niraula NP, Liou K, Sohng JK (2010) Identification of the duplicated genes for $S$-adenosyl-L-methionine synthetase (metK1sp and metK2-sp) in Streptomyces peucetius var. caesius ATCC 27952. J Appl Microbiol 109:398-407

Ohnishi Y, Ishikawa J, Hara H, Suzuki H, Ikenoya M, Ikeda H, Yamashita A, Hattori M, Horinouchi S (2008) Genome sequence of the streptomycin-producing microorganism Streptomyces griseus IFO 13350. J Bacteriol 190:4050-4060

Okamoto S, Lezhava A, Hosaka T, Okamoto-Hosoya Y, Ochi K (2003) Enhanced expression of $S$-adenosylmethionine synthetase causes overproduction of actinorhodin in Streptomyces coelicolor A3(2). J Bacteriol 185:601-609

Okamoto S, Tamaru A, Nakajima C, Nishimura K, Tanaka Y, Tokuyama S, Suzuki Y, Ochi K (2007) Loss of a conserved 7methylguanosine modification in 16S rRNA confers low-level streptomycin resistance in bacteria. Mol Microbiol 63:1096-1106

Okamoto-Hosoya Y, Okamoto S, Ochi K (2003) Development of antibiotic-overproducing strains by site-directed mutagenesis of the rpsL gene in Streptomyces lividans. Appl Environ Microbiol 69:4256-4259

Okamoto-Hosoya Y, Sato T, Ochi K (2000) Resistance to paromomycin is conferred by rpsL mutations, accompanied by an enhanced antibiotic production in Streptomyces coelicolor A3(2). J Antibiot (Tokyo) 53:1424-1427

Olano C, Lombo F, Mendez C, Salas JA (2008) Improving production of bioactive secondary metabolites in actinomycetes by metabolic engineering. Metab Eng 10:281-292

Onaka H, Mori Y, Igarashi Y, Furumai T (2011) Mycolic acidcontaining bacteria induce natural-product biosynthesis in Streptomyces species. Appl Environ Microbiol 77:400-406

Paudel S, Lee HC, Kim BS, Sohng JK (2011) Enhancement of pradimicin production in Actinomadura hibisca P157-2 by metabolic engineering. Microbiol Res 167:32-39

Qiu X, Yan X, Liu M, Han R (2012) Genetic and proteomic characterization of rроB mutations and their effect on nematicidal activity in Photorhabdus luminescens LN2. PLoS One 7:e43114

Rigali S, Titgemeyer F, Barends S, Mulder S, Thomae AW, Hopwood DA, van Wezel GP (2008) Feast or famine: the global regulator DasR links nutrient stress to antibiotic production by Streptomyces. EMBO Rep 9:670-675

Saito N, Kurosawa K, Xu K, Okamoto S, Ochi K (2003) Effect of $S$ adenosylmethionine on antibiotic production in Streptomyces griseus and Streptomyces griseoflavus. Actinomycetol 17:47-49

Santos CNS, Stephanopoulos G (2008) Combinatorial engineering of microbes for optimizing cellular phenotype. Curr Opin Chem Biol 12:168-176

Schneiker S, Perlova O, Kaiser O, Gerth K, Alici A, Altmeyer MO, Bartels D, Bekel T, Beyer S, Bode E, Bode HB, Bolten CJ, Choudhuri JV, Doss S, Elnakady YA, Frank B, Gaigalat L, Goesmann A, Groeger C, Gross F, Jelsbak L, Kalinowski J,
Kegler C, Knauber T, Konietzny S, Kopp M, Krause L, Krug D, Linke B, Mahmud T, Martinez-Arias R, McHardy AC, Merai M, Meyer F, Mormann S, Munoz-Dorado J, Perez J, Pradella S, Rachid S, Raddatz G, Rosenau F, Ruckert C, Sasse F, Scharfe M, Schuster SC, Suen G, Treuner-Lange A, Velicer GJ, Vorholter FJ, Weissman KJ, Welch RD, Wenzel SC, Whitworth DE, Wilhelm S, Wittmann C, Blocker H, Puhler A, Muller R (2007) Complete genome sequence of the myxobacterium Sorangium cellulosum. Nat Biotechnol 25:1281-1289

Schroeckh V, Scherlach K, Nutzmann HW, Shelest E, Schmidt-Heck W, Schuemann J, Martin K, Hertweck C, Brakhage AA (2009) Intimate bacterial-fungal interaction triggers biosynthesis of archetypal polyketides in Aspergillus nidulans. Proc Natl Acad Sci USA 106:14558-14563

Shima J, Hesketh A, Okamoto S, Kawamoto S, Ochi K (1996) Induction of actinorhodin production by $r p s L$ (encoding ribosomal protein S12) mutations that confer streptomycin resistance in Streptomyces lividans and Streptomyces coelicolor A3(2). J Bacteriol 178:7276-7284

Shin SK, Park HS, Kwon HJ, Yoon HJ, Suh JW (2007) Genetic characterization of two $S$-adenosylmethionine-induced ABC transporters reveals their roles in modulations of secondary metabolism and sporulation in Streptomyces coelicolor M145. J Microbiol Biotechnol 17:1818-1825

Sun LH, Li MG, Wang YS, Zheng YG (2012) Significantly enhanced production of acarbose in fed-batch fermentation with the addition of $S$-adenosylmethionine. J Microbiol Biotechnol 22:826-831

Sun Y, Cui C, Han X, Li C, Yang M (2010) Screening for bioactive mutants with antitumor activity from an actinomycetic wild-type strain without antitumor activity by antibiotic-resistant mutation technique and by coupled with chemical mutagen-induced mutation. Bull Acad Millit Med Sci 34:16-20

Takahashi K, Kasai K, Ochi K (2004) Identification of the bacterial alarmone guanosine 5 '-diphosphate $3^{\prime}$-diphosphate (ppGpp) in plants. Proc Natl Acad Sci USA 101:4320-4324

Tala A, Wang G, Zemanova M, Okamoto S, Ochi K, Alifano P (2009) Activation of dormant bacterial genes by Nonomuraea sp. strain ATCC 39727 mutant-type RNA polymerase. J Bacteriol 191:805814

Tamehiro N, Hosaka T, Xu J, Hu H, Otake N, Ochi K (2003) Innovative approach for improvement of an antibiotic-overproducing industrial strain of Streptomyces albus. Appl Environ Microbiol 69:64126417

Tanaka Y, Hosaka T, Ochi K (2010) Rare earth elements activate the secondary metabolite-biosynthetic gene clusters in Streptomyces coelicolor A3(2). J Antibiot (Tokyo) 63:477-481

Tanaka Y, Komatsu M, Okamoto S, Tokuyama S, Kaji A, Ikeda H, Ochi K (2009a) Antibiotic overproduction by $r p s L$ and $r s m G$ mutants of various actinomycetes. Appl Environ Microbiol 75:4919-4922

Tanaka Y, Tokuyama S, Ochi K (2009b) Activation of secondary metabolite-biosynthetic gene clusters by generating $r s m G$ mutations in Streptomyces griseus. J Antibiot (Tokyo) 62:669-673

Tozawa Y, Nomura Y (2011) Signalling by the global regulatory molecule ppGpp in bacteria and chloroplasts of land plants. Plant Biol (Stuttg) 13:699-709

van der Biezen EA, Sun J, Coleman MJ, Bibb MJ, Jones JD (2000) Arabidopsis RelA/SpoT homologs implicate (p)ppGpp in plant signaling. Proc Natl Acad Sci USA 97:3747-3752

van Wezel GP, McDowall KJ (2011) The regulation of the secondary metabolism of Streptomyces: new links and experimental advances. Nat Prod Rep 28:1311-1333

Vigliotta G, Tredici SM, Damiano F, Montinaro MR, Pulimeno R, di Summa R, Massardo DR, Gnoni GV, Alifano P (2005) Natural merodiploidy involving duplicated $r p o B$ alleles affects secondary metabolism in a producer actinomycete. Mol Microbiol 55:396412 
Wang G, Hosaka T, Ochi K (2008) Dramatic activation of antibiotic production in Streptomyces coelicolor by cumulative drug resistance mutations. Appl Environ Microbiol 74:2834-2840

Wang G, Inaoka T, Okamoto S, Ochi K (2009a) A novel insertion mutation in Streptomyces coelicolor ribosomal S12 protein results in paromomycin resistance and antibiotic overproduction. Antimicrob Agents Chemother 53:1019-1026

Wang L, Zhao Y, Liu Q, Huang Y, Hu C, Liao G (2012) Improvement of A21978C production in Streptomyces roseosporus by reporterguided $r p s L$ mutation selection. J Appl Microbiol 112:1095-1101

Wang XJ, Wang XC, Xiang WS (2009b) Improvement of milbemycinproducing Streptomyces bingchenggensis by rational screening of ultraviolet- and chemically induced mutants. Chem Mater Sci 25:1051-1056

Wang Y, Chu J, Zhuang Y, Zhang L, Zhang S (2007) Improved production of erythromycin A by expression of a heterologous gene encoding $S$-adenosylmethionine synthetase. Appl Microbiol Biotechnol 75:837-842

Wang Y, Liu Y, Zhu Y, Liu S, Cai C, Xu P (2006) Screening of high yield norvancomycin producing strain by streptomycin and rifampicin resistant mutation. Chin J Antibiot 31:243-246

Wenzel SC, Muller R (2009) The biosynthetic potential of myxobacteria and their impact in drug discovery. Curr Opin Drug Discov Devel 12:220-230
Williams RB, Henrikson JC, Hoover AR, Lee AE, Cichewicz RH (2008) Epigenetic remodeling of the fungal secondary metabolome. Org Biomol Chem 6:1895-1897

Xie S, Xiao J, Xu J (2009) Advance in microbial ribosome engineering. Wei Sheng Wu Xue Bao 49:981-986

Xu J, Tozawa Y, Lai C, Hayashi H, Ochi K (2002) A rifampicin resistance mutation in the $r p o B$ gene confers ppGpp-independent antibiotic production in Streptomyces coelicolor A3(2). Mol Genet Genomics 268:179-189

Yamada A, Tsutsumi K, Tanimoto S, Ozeki Y (2003) Plant RelA/ SpoT homolog confers salt tolerance in Escherichia coli and Saccharomyces cerevisiae. Plant Cell Physiol 44:3-9

Zhang Q, Zhu BQ, Hu HF (2008) Activated antibiotic production by inducing resistance to capreomycin in Streptomyces lividans and Streptomyces coelicolor. Chin J Nat Med 6:57-62

Zhao XQ, Gust B, Heide L (2010) S-adenosylmethionine (SAM) and antibiotic biosynthesis: effect of external addition of SAM and of overexpression of SAM biosynthesis genes on novobiocin production in Streptomyces. Arch Microbiol 192:289-297

Zhao XQ, Jin YY, Kwon HJ, Yang YY, Suh JW (2006) S-adenosylmethionine (SAM) regulates antibiotic biosynthesis in Streptomyces spp. in a mode independent of its role as a methyl donor. J Microbiol Biotechnol 16:927-932 